\title{
Crise, mutation et renouveau de la CULTURE FrançaISE SUR LES IDÉES DE DÉCLIN OU DE DÉCADENCE
}

\author{
PIERRE Rivas \\ Université Paris X Nanterre
}

\begin{abstract}
Depuis plusieurs années, la culture française - à l'égal de la littérature - fait l'objet d'attaques récurrentes sur un prétendu déclin de son rayonnement: effacement du maître à penser réduit à sa posture médiatique face à l'échec des idéologies, effacement de la théorie littéraire, mise en cause de l'exception culturelle, repli hexagonal étranger aux nouvelles théories postcoloniales, débats internes sur des modèles culturels alternatifs ou antagonistes. Ces thèses déclinistes, portées par des Français mais aussi par des étrangers, traduisent en fait une crise de la culture française mais dévoilent surtout la mutation et en fin de compte la résilience de la culture française face aux transformations du monde.
\end{abstract}

\section{Intellectuels - Postcolonial - Postmoderne - Post-idéologique - Post-national}

Un thème récurrent traverse la pensée française depuis quelques années: la culture et la littérature française seraient entrées en déclin et certains parlent même de décadence. Après les Trente Glorieuses (1945-1975), ce seraient les Trente Piteuses (BAVEREZ, 1998). Le thème est pareillement repris par les essayistes étrangers, en particulier anglo-saxons, Anderson à gauche (Anderson, 2010) et Morrison à droite (Morrison, 2008), entre autres. Après les grandes années théoriques - 1960-1970 -, celles du structuralisme et de la French Theory, la pensée française s'est provincialisée, ignorant les grands courants étrangers et se ralliant à l'ordre établi: la critique de la Révolution française et son sillage, avec F. Furet (Furet, Julliard et Rosanvallon, 1988) et les Lieux de mémoire (Nora, 1997) faisant de la France un musée, la muséification de sa culture. La France ne rayonne plus dans le monde: pays narcissique et conformiste. Les grands écrivains et penseurs - Sartre, Camus, Malraux, Braudel, Foucault, Barthes, Lacan, Bourdieu, Lévi-Strauss, Derrida, Deleuze - sont sans postérité. Pour Perry Anderson (2005), les grands "scientistes" formés dans les grandes écoles littéraires - École Normale Supérieure - avaient une culture générale littéraire, philosophique; ils ont été remplacés par l'ENA, HEC, etc.: ce ne sont plus des intellectuels mais des

* Maître de conférences honoraire de Littérature comparée Université Paris X Nanterre. 
technocrates ou des "intellectuels médiatiques" avec le règne de la télévision. Une pensée "tiède", modérée, avec la fin de l'hégémonie marxiste et de la culture humaniste et critique. C'est la fin de "l'exception française" (Furet, 1988), la victoire du modèle anglo-saxon, du néolibéralisme et donc, avec le déclin de la langue française, de la "pensée unique", la victoire de l'expert sur l'intellectuel, l'effacement de ce dernier.

La victoire de Mitterrand (1981) aurait réveillé la peur du communisme; Mai 68 et son élan libertaire auraient conduit les ex-gauchistes, sous couvert de lutte antitotalitaire (lecture de Soljenitsyne; rôle de Pol-Pot au Cambodge; désillusions à Cuba et dans le Tiers Monde; conflit israélo-palestinien) et à travers l'idéologie des Droits de l'Homme et du devoir d'ingérence (Yougoslavie, etc.) à devenir "les nouveaux réactionnaires" (Lindenberg, 2002). C'est le règne "des Piètres penseurs" (Lecourt, 1999), de la Révolution conservatrice (Eribon, 2007), de la Décennie, grand cauchemar des années 80 (Cusset, 2006).

Cette idéologie des Droits de l'Homme (B.H. Lévy, Kouchner, etc.) ne peut faire, de l'aveu même de F. Furet, une politique; elle sape l'idée même de nation; pire encore, le messianisme politique justifie une politique néo-impérialiste (Irak, Libye, etc.), comme le dénonce Todorov (2012). La repentance, le devoir de mémoire divisent la nation et instrumentalisent 1'Histoire. Ces "idéologies" pseudo-libérales aboutissent à des exigences contradictoires, entre Droits du Citoyen et Droits à la Différence, revendiqués par les "minorités visibles", entre multiculturalisme à l'américaine et héritage d'une République une, indivisible et laïque, entre micro-cultures (régionales, ethniques, raciales, sexuelles, religieuses) et identité nationale; la repentance affaiblit la force d'adhésion à la Nation, qui, selon l'analyse de Renan, exige qu'on oublie les pages sombres de l'Histoire. Contre ceux qui, comme B.-H. Lévy, dénoncent "l'idéologie française", avec ses amis ex-gauchistes Glucksmann, Finkielkraut -, les "souverainistes" comme Régis Debray (1979) dénoncent le multiculturalisme; d'où des questions qui divisent les intellectuels et l'opinion: le problème de l'école, lieu de l'épanouissement de l'élève ou de transmission du savoir (Finkielkraut, 2007). La "guerre" des intellectuels divise les "républicains" et les "démocrates" selon Régis Debray, d'un côté les défenseurs d'un pouvoir vertical (ordre, savoir respect de l'autorité), hostiles au libéralisme économique et méfiants face au libéralisme sociétal et à l'Europe supranationale, et de l'autre, ceux que Debray appelle les "démocrates": libéraux en économie et en matière de mœurs; d'un côté, la tradition jacobine, de l'autre, des post-nationaux. Le procès porte sur la culture de masse, le métissage, l'égalitarisme, l'héritage de Mai 68, le féminisme, le mariage gay, la fonction de l'école, etc. Pour certains, l'héritage libertaire de Mai 68 aurait conduit au néolibéralisme: le journal Libération, passant de Mao à Rothschild (Pierre Rimbert, 2005); la même "ruse de l'histoire" aurait vu l'arrivée de la gauche au pouvoir conduire au triomphe de la droite intellectuelle (on pense ici aux analyses de Roger Bastide sur la sociologie de la culture: les périodes de conservatisme créent des formes de pensées contestataires; les périodes réformatrices, des pensées conservatrices). Ces remarques expliquent l'inflexion de la posture de l'intellectuel. On passe de l'intellectuel généraliste, tradition française de Voltaire à Sartre, jugeant au nom de l'universel et accompagnant les grands combats libérateurs, à l'intellectuel spécifique (Foucault) et à l'intellectuel collectif (Bourdieu) et, avec la crise à partir de 1980, au déclin de l'intellectuel et de son effacement, avec l'ère des médias et la figure de l'intellectuel médiatique (B.-H. Lévy) puis la fin de l'intellectuel au profit de l'expert, le technocrate, dont la 
fonction est de mettre de l'huile dans les rouages plutôt que la transformation du monde.

Michel Foucault annonçait dans les Mots et les choses "la disparition du grand écrivain"; c'est aussi la fin du grand intellectuel avec la fin des grands systèmes métahistoriques et avec l'avènement de la société du spectacle. Les "intellectuels" aujourd'hui publient dans ce que Raymond Boudon appelle "le second marché": les hebdomadaires, les médias; ce sont des journalistes essayistes, des vulgarisateurs polémistes, qui seraient passés de Marx à Tocqueville et de Tocqueville à Leo Strauss, le maître des néo-conservateurs américains, dans une vague réactionnaire et réactionnelle, se recommandant de Ph. Muray (2007), N. Baverez La France qui tombe: un constat clinique du déclin français (2003), etc.

Le livre de Cusset, La décennie, le grand cauchemar des années 1980 (2007) est un réquisitoire accablant sur les années Mitterrand: la gauche serait passée de Lénine à Lennon et de Staline à Stallone, de l'intellectuel à l'essayiste mondain; l'esprit de la Révolution est passé dans l'entreprise; règne du fric et de la frime: Tapie, Jack Lang; Libération est passé de Sartre à Rothschild (2005). Pour Debray, le théâtre, après Jean Vilar, est tombé de Gramsci à Gucci, victoire de la Foire sur le Festival (2005). Jean Clair dénonce l'imposture de l'Art Moderne (1997): tous dénoncent les dérives d'une avant-garde dévoyée et la fin de la modernité.

C'est surtout la littérature et son supposé déclin qui sont l'objet d'attaques multiples, et, d'abord, la mise en cause de la théorie littéraire et son influence malfaisante sur l'École et sur la littérature. La dénonciation est portée par d'anciens théoriciens, de même que ce sont d'anciens intellectuels maoïstes qui sont devenus les plus réactionnaires. Avec l'effacement du grand intellectuel, c'est aussi l'effacement et même l'effondrement de la théorie littéraire, qui furent tous deux un grand moment de rayonnement international.

Pour Todorov (2006), c'est elle qui est responsable, avec son hégémonie dans l'enseignement, du discrédit de la littérature: "on n'apprend pas de quoi parlent les œuvres, mais de quoi parlent les critiques". L'emprise de la théorie aurait stérilisé la création littéraire qui se résumerait en formalisme, solipsisme, nihilisme, narcissisme; autofiction et autoréférentialité, autotélisme, d'où la perte du rayonnement de la littérature française dans le monde. Or la littérature est un discours sur le monde; Jacques Bouveresse (2008), salut la fin, désormais, du cycle de "la bigoterie structuraliste", dernier avatar de la "bigoterie littéraire": Blanchot, Barthes, l'intransitivité littéraire, ultime chaînon de la théorie de l'art pour l'art. "La littérature est un dévoilement du monde et de l'homme, elle a trait à l'existence humaine".

On trouve une même attaque et une même analyse chez Antoine Compagnon (2007), exélève, comme Todorov, de Barthes. Compagnon s'est expliqué avec un journaliste américain qui avait publié un article sur la "Death of French culture". Cet article et la réponse de Compagnon sont réunis dans Que reste-t-il de la culture française, suivi de le Souci de la grandeur (2008). Morrisson reprend le thème décliniste: la langue française est en chute libre, il n'y a plus de grands penseurs ni de grands écrivains; on ne traduit plus cette littérature; le cinéma français n'a plus l'éclat de la Nouvelle Vague; il n'y plus de peintres français reconnus internationalement. Paris n'est plus la capitale internationale de l'Art. Pour Morrisson, la faute en est à la politique culturelle française, à "l'exception culturelle", qui en font un marché protégé, subventionné; d'où des films hexagonaux et inexportables; des romans intimistes, nombrilistes, cérébraux. (Le Jornal de letras demande régulièrement à ses lecteurs ce qu'ils lisent: "O que anda a ler" - il est rare que ce soit un titre français). Pour Morrisson, c'est un 
cinéma sans public, une littérature sans lecteurs; les bestsellers (Marc Lévy, Amélie Nothomb, le théâtre de Yasmina Reza), sont snobés par une petite élite.

Ces reproches sont typiquement américains: c'est une approche mercantiliste, néoconservatrice, qui renvoient à l'aspect très provincial et autocentré de la culture américaine (reproche, donc, en miroir): les États-Unis ne traduisent pas de littérature étrangère, la France aide la traduction littéraire et les cinémas étranges (Manoel de Oliveira par exemple), l'art ne se réduit pas au marché; les Américains se disent ultra-libéraux, mais en fait protègent leur marché intérieur: Hollywood comme le maïs; c'est un marché fermé; "l'exception culturelle" française ignorerait les minorités; elle plaide pour la diversité culturelle contre l'hégémonie américaine. En fait, comme le rappelle Compagnon, la culture en France a toujours été liée, depuis François Ier, à l'État; la France est une "Nation culturelle"; la culture est un élément constitutif de son identité et de son rayonnement international.

Pour un Français, l'art relève de l'otium et pas du négoce, de la contemplation, de la lecture. C'était déjà la critique d'un académicien conservateur comme Marc Fumaroli. Il avait dénoncé l'État culturel en France (1990), s'en prenant à J. Lang. Il récidive avec Paris-New York et Retour, Voyage dans les Arts et les images (2009); lui aussi, comme Morrisson, critique le rôle de l'État et du ministère de la Culture, mais pour dénoncer sa marchandisation, que déteste cet élitiste réactionnaire; le marché américain a fait du dandy Marcel Duchamp le héros de la modernité avec sa postérité: Andy Warhol, Damien Hirst (à Versailles), l'art est devenu un cirque où le marché recycle au gré de la spéculation, de pseudo-artistes: monde des images, des musiques trépidantes, des Maisons de la Culture de Malraux; les expositions sont des événements sociaux où se pressent une foule sans rencontre intime avec le chef-d'œuvre. "Le lent effacement de l'art français sur la scène mondiale" (expression de Ph. Dagen ) s'explique, selon Jean Clair (2007) parce que "la culture s'est détachée du culte et s'est faite culte elle-même". Elle n'est plus qu'un "déchet... On est passé du culte à la culture et de là au tout culturel: la foire, le bavardage, la philosophie de café, le spectacle, le spectaculaire" comme l'avaient annoncé Guy Debord, Baudrillard, les situationnistes.

C'est la fin de l'intime, de la sacralité de l'art; la modernité a sombré dans la "merdonité" (Leiris), à travers trois étapes: le sacré, le profane, le ludique. Ces imprécateurs refusent "la mondialisation heureuse" (Minc, 1997), la modernolatrie, le nomadisme (Attali). La scène littéraire est ainsi marquée par la détestation de la modernité, jusqu'à des positions réactionnaires voire ouvertement xénophobes avec Renaud Camus ou Richard Millet, "la haute bigoterie du politiquement correct" des néo-réactionnaires, néo-conservateurs et néo-fascistes, "le crachat pseudo-aristocratique" (Michel Crépu) contre le multiculturalisme, les communautarismes ethniques, sexuels, mémoriels et le prétendu péril musulman. Pour Richard Millet, avec le métissage et l'antiracisme, "la langue s'est du point de vue du style, effondrée dans la démocratie... C'est pourquoi il n'y a plus de grand écrivain... La France est morte" (Millet, 2007); depuis Camus et Millet ont écrit pire, se déportant vers l'inacceptable.

Mais on trouve une même détestation chez des gens venus de l'ex-extrême gauche: Régis Debray (2007). Antoine Compagnon concède que la langue française a perdu de son hégémonie; il regrette la politique culturelle de la France, faite de saupoudrage; il reconnaît que la pensée française a trop longtemps ignoré le tournant postcolonial dont pourtant une des sources était la French Theory; de même l'Histoire, un des points forts, longtemps, de la 
France, est restée dominée par l'École des Annales, ignorant l'Histoire globale ou Interconnectée en vogue aux États-Unis.

Pour beaucoup d'intellectuels français - de droite ou de gauche -, le multiculturalisme est un danger dans un vieux pays centralisé, contrairement aux pays d'immigration du Nouveau Monde où les thèmes de la migrance, de l'hybridité, du métissage, ont un sens. Pour les conservateurs français, ces théories affaiblissent la Nation; pour la gauche, elles démobilisent le peuple; la lutte des races fait déserter la lutte des classes, et il en est de même pour la lutte des sexes; ce serait une stratégie insidieuse de l'ultralibéralisme, phase ultime de l'hédonisme de Mai 68, contre le marxisme longtemps hégémonique. Ce n'est pas l'opinion ni l'émotion mais la raison et la conviction qui doivent conduire la démocratie.

Le multiculturalisme conduit à une ethnicisation (Amselle, 2011) du pays avec ses dérives, dressant les communautés entre elles: rivalité mimétique des lois mémorielles (loi Gayssot contre le négationnisme; loi Taubira contre l'esclavage, etc.) détournant du combat politique. Les "cultural and subaltern studies" et les études de genre ont envahi les universités américaines et remplacé les études de langue et littérature européennes, qui, selon Compagnon, sont en chute libre. Pour les Français, les études postcoloniales (Bayard, 2010) restent en fait prisonnières du culturalisme et du récit national dont elles prétendent émanciper les sciences sociales; elles instrumentalisent les "minorités actives" socialement rejetées en rejetant la faute sur la "fracture" coloniale plutôt que sociale; elles solidifient les "identités meurtrières" (Amin Maalouf, Grasset, 1998); le tiers-mondisme est un alibi démobilisateur: Alain Mabanckou, dans le Sanglot de l'homme noir (2012) fait écho, en ce sens, à Pascal Bruckner et son Sanglot de l'homme blanc (1983). De la même manière, l'idéologie écologiste bobo oublie le prolétaria; le thème de la décroissance est en phase avec les politiques ultra-libérales. On a fait de pareilles analyses concernant les études de genre qui prétendent opérer une critique des normes et des natures tout en se coulant dans un langage sexualiste; "en se proposant de brouiller les identités sexuées, elles finissent par fossiliser la plasticité identitaire sombrant dans une sorte de sexo-centrisme. Régis Debray oppose le modèle américain, mosaïque de minorités mais transcendé par un patriotisme messianique adossé à un Dieu confédéral, à la France dont le seul ciment est la Nation; là où l'État s'effondre triomphent le tribalisme, l'ethnie, les clergés, les intégrismes, le repli communautaire, c'est-à-dire la guerre de tous contre tous - compensée par une idéologie "humanitaire": le devoir d'intervention (Irak, Libye), stratégie des puissances impériale et leurs mécomptes, Todorov dénonçant le messianisme humanitaire (Todorov, 2012). Ce thème multiculturaliste, si dénoncé par les intellectuels, cet éloge du métissage a trouvé sa fonction dans la littérature. Face au thème de la décadence de la littérature, il y aurait une fertilité des marges et des littératures émergentes, ce que Milan Kundera appelle "le roman du Sud: Rabelais, l'oralité, l'invraisemblance, Garcia Marquez, Rushdie, Chamoiseau". C'est le thème du manifeste de Michel Le Bris (2007). Contre le nihilisme parisien, s'ouvrir à une littérature voyageuse, métissée; non plus l'identité atavique, mais la "relation archipélique" (Glissant), non le Moi, mais le Monde; non la centralité parisienne mortifère mais les périphéries ; non la Francophonie réduite à un tête-àtête avec la France, mais la créolisation. L'instance de légitimation n'est plus Paris, qui perd son rang de capitale littéraire internationale, mais la déterritorialisation. En fait, ce Manifeste se réduit à une attaque des Postcoloniaux contre les Postmodernistes, de la Province contre 
Paris; c'est un essai de stratégie littéraire de reconnaissance, non sans boursouflure ni mauvaise foi (le pacte qui lierait la francophonie à la Nation française), même si le cosmopolitisme global issu de la mondialisation pourrait alimenter "ces cultures de la contre-modernité, résistant à leurs oppressives technologies assimilationnistes" pour citer Homi K. Bhabha (2007).

La critique la plus constante sur le prétendu déclin français serait la fin des grands écrivains (Malraux, Sartre, Camus, etc.) et des grands penseurs. Le Sacre de l'écrivain (Bénichou, 1996) a perdu son emprise, son prestige social, sa puissance formatrice. Roland Barthes disait dans sa Leçon au Collège de France, "Depuis la Libération, le mythe du grand écrivain, dépositaire sacré de toutes les valeurs supérieures, s'effrite, s'exténue et meurt peu à peu avec les derniers survivants de l'entre-deux-guerres; c'est un nouveau type qui entre sur la scène dont on ne sait plus ou pas encore l'appeler: écrivain, intellectuel, scripteur. De toute façon, la maîtrise littéraire disparaît; l'écrivain ne peut plus faire parade". Ces mutations recoupent le changement de paradigme culturel. Il n'y a plus de grand écrivain parce qu'on est entré dans une ère postmoderne; il n'y a plus de grand penseur parce qu'on est entré dans l'ère post-idéologique avec la faillite des grandes utopies révolutionnaires, la fin du communisme, des grands systèmes métahistoriques, des désillusions postcoloniales. Avec la fin, donc, des grands affrontements qui faisaient la vie des grands débats: Sartre contre Camus, Furet contre Bourdieu, Aron contre Althusser. Les clivages ont disparu ou se sont amoindries (mais on a vu plus haut la persistance de la ligne de fracture entre nationaux et postnationaux). On a parlé de fin de l'histoire, du triomphe de la démocratie; le paysage culturel a changé. Avec la fin de la culture humaniste, le triomphe de la technique, de l'économie, des médias, il n'y aurait plus pour l'intellectuel que deux manières de se singulariser dans l'inculture générale: l'intellectuel médiatique (B.-H. Lévy) ou la radicalité révolutionnaire (Badiou: le Dernier des Mohicans).

Mais la crise de l'ultra-libéralisme montre aussi la faillite de l'expert qui s'est autant décrédibilisé que l'intellectuel avec la crise économique. On assiste à un renouveau de la pensée critique, relayant l'utopie historique, entre héritage et mutation, repensant de nouvelles configurations (Badiou, 2005; Keucheyan, 2010).

La notion de déclin de la culture française a une histoire: le thème est obsédant dans les années 30 déjà; la défaite de 1940 a fait perdre à la France son rang de grande puissance; son prestige a perduré un temps à travers les mythologies nationales du gaullisme et du communisme, puis de l'anticolonialisme. Depuis, l'Europe, le marché, la mondialisation ont mis fin à l'exception culturelle (on préfère parler désormais de combat pour la diversité). C'est parce que le rayonnement français a connu un éclat exceptionnel que ce sentiment du déclin est plus vif. La culture est la seule forme de puissance pour la France à mesure que s'affaiblissent sa puissance économique et militaire, depuis les deux guerres mondiales.

En France, la culture a toujours été une affaire d'État, de son rayonnement, de sa grandeur. La nostalgie française face aux mélancolies du moderne et une si longue histoire explique ces crises: affronter l'avenir à la lumière d'un héritage prestigieux et encombrant. Pour Tocqueville, si le passé n'éclaire pas le présent, il obère alors l'avenir. La culture, c'est, disait Hannah Arendt, "la patrie immortelle des hommes mortels"; d'où le poids de l'héritage: "faire une œuvre filiale", selon Barthes; "empêcher que le monde se défasse" selon A. Camus.

Mais l'idée de décadence est un pseudo-concept, à l'égal de toutes les idées négatives, 
comme l'a montré Bergson. Il faut plutôt parler de crise, moment, selon Gramsci, entre ce qui ne veut pas mourir et ce qui est en train de naître: c'est en ce sens, comme le montre Myriam Revault d'Allonnes (2012), un moment dynamique, un paroxysme assurant la transition d'une période à une autre; le pathos de la décadence est le pendant de l'idéologie du progrès, deux notions liées historiquement. Il convient plutôt de parler de mutation et de renouveau, qu'on a peine encore à définir et à dessiner; mais la résilience de la culture et de la littérature françaises est manifeste à tout esprit attentif au travail du négatif - celui de la vieille taupe - et, contre les vieux ronchons réactionnaires qui sont dans la posture et dans l'imposture, l'incertain à venir s'avance sur des pas de colombe.

\section{Références bibliographiques}

AMSELLE, Jean-Loup. L'Ethnicisation de la France. Le Havre: Ligne, 2011.

ANDERson, Perry. La Pensée tiède, un regard critique sur la culture française. Suivi de La Pensée réchauffée, réponse de Pierre Nora. Paris: Seuil, 2005.

BADIOU, Alain. Le Siècle. Paris: Seuil, 2005.

BAVEREZ, Nicolas. Les Trente piteuses. Paris: Flammarion, 1999.

La France qui tombe : Un constat clinique du déclin français. Paris: Perrin, 2003.

BAYARD, Jean-François. Les Études postcoloniales. Un carnaval académique. Paris: Karthala, 2010.

BÉNICHOU, Paul. Le Sacre de l'écrivain. 1750-1830. Essai sur l'avènement d'un pouvoir spirituel laïque dans la France moderne. Paris: Flammarion, 1996.

BHABHA, Homi K. Les Lieux de la culture. Une théorie postcoloniale. Paris: Payot, 2007. 2008

BOUVERESSE, Jacques. La Connaissance de l'écrivain, sur la littérature, la vérité et la vie. Marseille: Agone,

BRUCKNER, Pascal. Le Sanglot de l'homme blanc. Paris: Seuil, 1983.

CLAIR, Jean. La Responsabilité de l'artiste. Paris: Gallimard, 1997.

. Malaise dans les musées. Paris: Flammarion, 2007.

CUSSET, François. La Décennie: Le grand cauchemar des années 1980. Paris: La découverte, 2006.

. French Theory. Foucault, Derrida, Deleuze \& Cie et les mutations de la vie intellectuelle aux Etats-

Unis. Paris: La Découverte, 2005.

DEBRAY, Régis. Le Pouvoir intellectuel en France. Paris: Ramsay, 1979.

. Sur le pont d'Avignon. Paris: Flammarion, 2005.

L'Obscénité démocratique. Paris: Flammarion, 2007. 2007.

ERIBON, Didier. D'une révolution conservatrice : Et de ses effets sur la gauche française. Paris: Léo Scheer,

FINKIELKRAUT, Alain. Qu'est-ce que la France. Paris: Stock, 2007.

FUMARoLI, Marc. L'État culturel. Essai sur une religion moderne. Paris: Fallois, 1998.

. Paris-New York et retour. Voyage dans les arts et les images. Paris: Fayard, 2009.

FURET, François, Jacques JULLIARD et Pierre ROSANVALLON. La République du centre, la fin de l'exception française. Paris: Calmann-Lévy, 1988.

GLISSANT, Édouard. Introduction à une poétique du divers. Paris: Gallimard, 1996. 2010

KEUCHEYAN, Razmig. Hémisphère gauche. Une cartographie des nouvelles pensées critiques. Paris: Zones,

LE BRIS, Michel. Pour une littérature monde. Paris: Gallimad, 2007.

lecourt, Dominique. Les Piètres penseurs. Paris: Flammarion, 1999.

LEVY, Bernard-Henri. L'Idéologie française. Paris, Le livre de poche, 1998. 
LINDENBERG, Daniel. Le Rappel à l'ordre: Enquête sur les nouveaux réactionnaires. Paris: Seuil, 2002. MAALOUF, Amin. Les Identités meurtrières. Paris: Grasset, 1998.

MANBANCKOU, Alain. Le Sanglot de l'homme noir. Paris: Fayard, 1998.

MILLET, Richard. Désenchantement de la littérature. Paris: Gallimard, 2007.

MINC, Alain. La Mondialisation heureuse. Paris: Plon, 1997.

MORRISON, Donald. Que reste-t-il de la culture française. Suivi de COMPAGNON, Antoine. Le Souci de la grandeur. Paris: Denoël, 2008.

MURAY, Philippe. Après l'histoire. Paris: Gallimard, 2007.

NORA, Pierre (dir.). Les Lieux de mémoire. Paris: Gallimard, 1997.

La Pensée réchauffée. Un regard critique. Réponse de Pierre Nora. Paris: Le Seuil, 2005. 2012.

REVAULT D'AlLONNES, Myriam. La Crise sans fin. Essai sur l'expérience moderne du temps. Paris: Seuil,

RIMBERT, Pierre. Libération de Sartre à Rothschild. Paris: Raisons d'agir, 2005.

TODOROv, Tzvetan. La Littérature en péril. Paris: Flammarion, 2006.

. Les Ennemis intimes de la démocratie. Paris: Robert Laffont, 2012. 